\title{
Development and validation of a guide for the continuity of care in perioperative medication management
}

\author{
Carmen Matoses-Chirivella ${ }^{1 *}$, Andrés Navarro-Ruíz and Blanca Lumbreras ${ }^{2,3}$
}

\begin{abstract}
Background: Increased longevity and the prevalence of associated pathologies is leading to more hospital admissions involving chronic patients with multiple pathological problems. In orthopedic surgical patients, it is very important to individually evaluate the risk/benefit of maintaining or suppressing chronic medications. For certain medications, there are consensus recommendations, but for others, the available information may be limited or controversial.
\end{abstract}

Objective: To develop and validate a new guide for the continuity of care in perioperative medication management in older orthopedic surgical patients.

Materials and methods: An expert pharmacist developed the guide by systematically reviewing each medication category according to the Anatomical Therapeutic Chemical (ATC) classification system. The Pharmacy and Therapeutics Committee at the Hospital General Universitario de Elche reviewed the guide. After a training course on the guide for pharmacists, the guide was validated by studying the interobserver variability between pharmacists as well as between each pharmacist and the expert pharmacist. Cohen's kappa index ( $k$ ) was applied to determine interrater reliability.

Results: The guide includes 51 therapeutic groups. Each ATC pharmacological subgroup is structured according to the benefits and risks of continuing therapy. When we compared each pharmacist's recommendations with those of the expert pharmacist, the kappa value was found to be $0.8[95 \% \mathrm{Cl}(0.7,0.9)]$, indicating almost perfect concordance (overall percentage agreement 89.3\%).

Conclusions: We developed a guide for the continuity of care in perioperative medication management to improve the rationalization of medicines in the perioperative environment. After the pharmacists had been trained, the guide was validated by demonstrating a high level of concordance among the pharmacists' recommendations. Formal training seems to be essential to ensure consistency in medical decisions.

Level of evidence: IV (Oxford Centre for Evidence-Based Medicine. http://www.cebm.net/index.aspx?o=5653).

Keywords: Perioperative medication management, Guide, Concordance, Pharmacist

\section{Introduction}

Chronic medication management is essential in order to provide optimal care for the older orthopedic surgical patient. The purpose of the study reported here was to provide guidance to health care professionals on medication management during the perioperative period.

\footnotetext{
*Correspondence: matoses_car@gva.es

${ }^{1}$ Department of Pharmacy Services, University Hospital of Elche, Camino de la Almazara 11, 03203 Elche, Spain

Full list of author information is available at the end of the article
}

In 2015, global life expectancy at birth was 76.8 years in the World Health Organization (WHO) European Region [1]. The prevalence of comorbidities in the elderly is high, with $80 \%$ of this population having three or more chronic conditions [2]. Increases in longevity and the prevalence of associated pathologies are reflected in the fact that most hospital admissions involve chronic patients with multiple pathological problems $[3,4]$. The rising population aged more than 64 years has also resulted in a higher than expected prevalence and incidence of bone fractures [5]. 
In recent years, a significant proportion of medication errors have occurred during transitions between levels of care, especially during admission and discharge [6]. In 2005, the WHO launched the Action on Patient Safety initiative, also known as the High 5 s project, to address issues related to the safety of patients around the world [7]. This initiative includes, among others, a protocol to assure medication accuracy at transitions in care or medication reconciliation. In hospitals that implemented this protocol, the morbidity and mortality associated with medication errors were reduced by $32 \%[8]$.

Kennedy et al. [9] carried out a prospective survey to identify drug usage/withdrawal in surgical patients and its relationship to the relative risk for postoperative surgical complications. The researchers concluded that at least $50 \%$ of patients who were undergoing surgery took medications on a regular basis that were not related to their surgery. Moreover, they stated that withdrawing regular medicines may significantly increase the risk of surgery and further complicate the outcome.

Clinicians must often decide whether chronic medications should be continued during the perioperative period. Unfortunately, there is a lack of medical evidence in this regard, which is reflected in considerable variability in perioperative management recommendations. Kroenke et al. [10] assessed opinions regarding the preoperative discontinuation or modification of selected medications by mailing a questionnaire to all 150 anesthesiology program directors in the United States. The responses highlighted great variation in practice medication management, reflecting a lack of firm evidence favoring any one approach.

Among orthopedic surgical patients, it is very important to individually evaluate the risk/benefit of maintaining or suppressing chronic medications, which will depend partly on the drug and the type of surgical intervention, but most importantly on the clinical status of the patient [11]. However, given the lack of sound evidence on this topic, clinicians base their decisions on expert opinions, isolated clinical cases, or theoretical considerations based on experience with similar drugs [12].

Hence, it is necessary to gather together and evaluate the available recommendations for maintaining or suppressing chronic medications during the perioperative period [13, 14], and then to use this information to produce a guide for the continuity of care in perioperative medication management. Such a guide could help hospital pharmacists to ensure the continuity of chronic pharmacotherapeutic treatment, thereby avoiding unnecessary interruptions and searches for therapeutic alternatives. However, this guide would not be a substitute for clinical judgment and experience.
The aim of the present study was therefore to develop (by reviewing the available evidence) and to validate a new guide for the continuity of care in perioperative medication management, which could aid pharmacists and surgeons who need to manage chronic medications in older adults during the perioperative period.

\section{Materials and methods Study design}

The development of the guide for the continuity of care in perioperative medication management was based on a literature search and an external review by an expert committee. The guide was validated through a prospective, noninterventional cohort study. The flow of the study process is illustrated in Fig. 1.

\section{Development of the guide}

The guide was formulated by an expert pharmacist (CM) by systematically reviewing the available evidence for each medication class, based on the Anatomical Therapeutic Chemical (ATC) classification system developed by the European Pharmaceutical Market Research Association [15]. It includes the most consumed ATC pharmacological subgroups according to data for the year 2014 from the Ministry of Health, Social Services and Equality of Spain [16].

Recommendations were based on three concepts: the pharmacokinetics of the drug, the effect of withdrawing the medication on the primary disease, and the effect of the medicine on the perioperative risk, including potential interactions with anesthetic agents.

For the literature search, a consistent process was applied, based on:

1. Drug information (technical data sheet).

2. Micromedex ${ }^{\circledR}$. Provides summaries and detailed monographs for drugs, diseases, alternative medicine, toxicological managements, reproductive risks, and emergency care. It includes the following drug information databases:

- DRUGDEX ${ }^{\circledR}$ system. Dosage, pharmacokinetics, cautions, interactions, clinical applications, and comparative drug efficacy.

- MARTINDALE. Electronic version of the Martindale textbook published by the Royal Pharmaceutical Society of Great Britain. Offers extensive information on international drug products. Especially useful when searching for European drugs, and can be searched by brand name or generic name. 


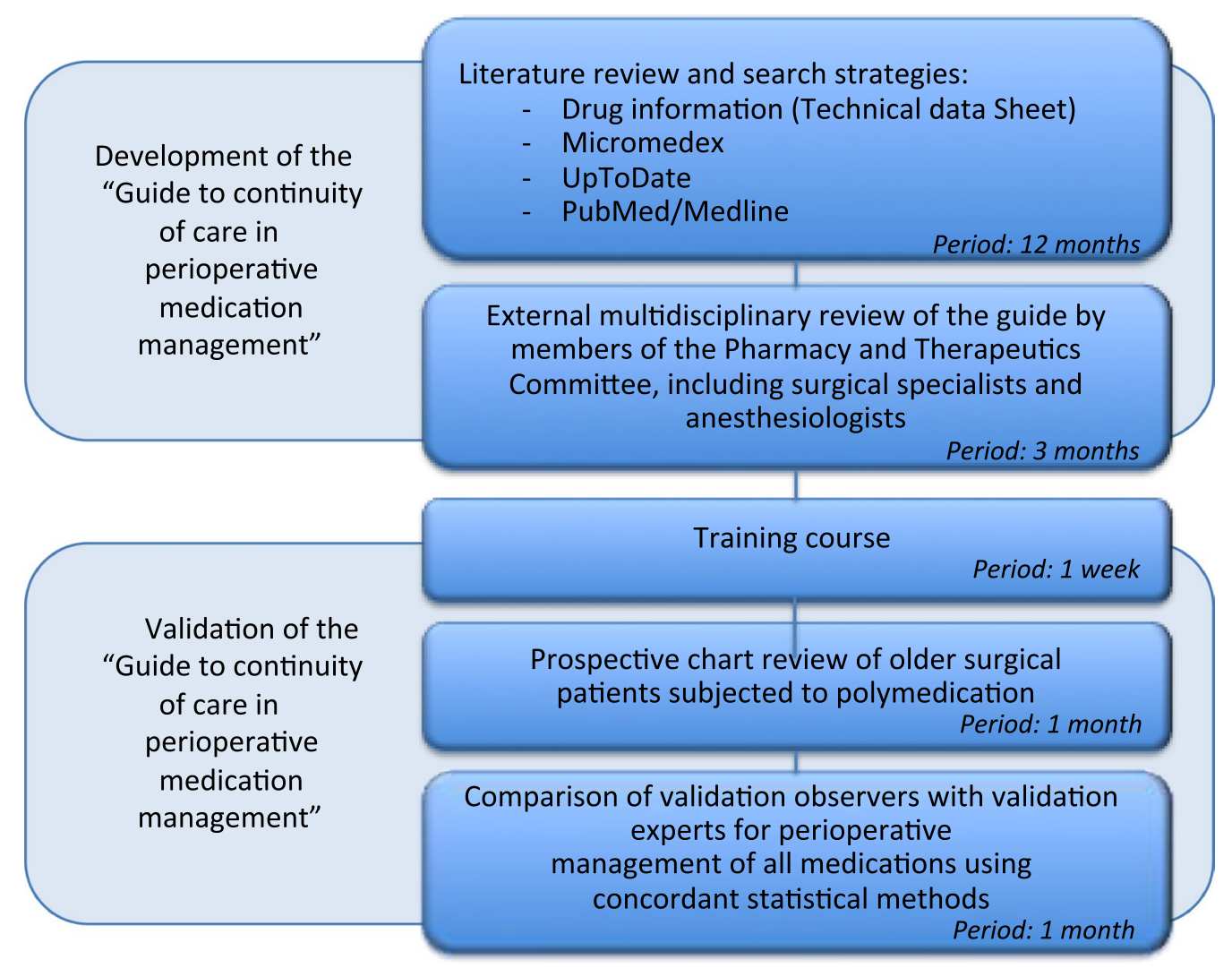

Fig. 1 Study design

- Alternative medicine. Includes monographs on herbal, vitamin, mineral, and other dietary supplements, based on scientific evidence as well as historical and common uses.

3. UptoDate $^{\circledR}$. An evidence-based, physician-authored clinical decision support resource that clinicians trust to make the right point-of-care decisions. Muluk and Macpherson provide an overview of preoperative patient assessment as well as details about the perioperative management of specific medications [12].

4. PubMed ${ }^{\circledR}$. Online database of biomedical journal citations and abstracts. The search strategy was similar to that applied by Lievanos Rojas in his thesis Perioperative management of chronic medications in orthopaedic surgery. A systematic review of the literature [17].

Finally, an external multidisciplinary review of the guide was performed by members of the Pharmacy and Therapeutics Committee at the Hospital General Universitario de Elche, including surgical specialists and physicians from the Department of Anesthesiology, who contributed their experience in clinical practice.

\section{Validation of the guide}

The guide was validated by performing an interobserver variability study.

\section{Participants}

An expert pharmacist $(\mathrm{CM})$ with 15 years of experience in the pharmacotherapeutic validation of medical orders was responsible for developing the guideline, and acted as the gold standard. She determined the correct action to perform regarding usual chronic treatments in the perioperative environment according to the clinical status of the patient.

The observers comprised eight pharmacists with different levels of professional experience who were working in the same hospital. There were three staff pharmacists, all of whom had clinical and pharmacological knowledge and a wide range of experience in the pharmacotherapeutic validation of medical orders; five resident pharmacists, two of whom were residents in their first year and thus had little knowledge of the practical application of drugs; and three other resident pharmacists in their second or third year of residency, who had more experience in validating the pharmacotherapeutic profiles of patients. 


\section{Training course}

The course was given by the expert (CM). The concepts covered in the session addressed the following five questions:

1. Why was the guide created? She explained that the purpose of the guide was to ensure the continuity of pharmacotherapeutic information, reduce variability in clinical practice, exceed the needs of the patient at all times during the perioperative period by improving safety, and improve the efficiency of the medication utilization process.

2. How is the guide structured? She presented a brief summary of the format of the guide, including its structure according to the ATC classification, as well as the benefits and risks of continuing or discontinuing medication in the perioperative environment.

3. How are the chronic medications grouped according to perioperative recommendations? She described simple concepts for the following situations:

3.1. Drugs that can increase morbidity if they are discontinued abruptly. Their use should continue in the perioperative period, or the treatment can be adjusted if possible.

3.2. Drugs that increase the risk of anesthetic medications or complications during surgery and which are not essential in the short term. These drugs should be suspended during the perioperative period.

3.3. Drugs that do not belong to any of the previous groups. These may be suspended or continued according to clinical criteria.

4. What basic pharmacological concepts do we need to know? She gave participants a brief overview of the most relevant drug interactions as well as descriptions of metabolic processes and the elimination of drugs and their metabolites, and she discussed how these can be altered in the perioperative period.

5. How should I act if I have any doubt? She stressed the importance of agreeing with clinic staff (either the orthopedic surgeon responsible for the patient or another relevant medical specialist) on the action to be taken in the event of clinical instability of the patient, or if there is doubt about the typical chronic treatment.

\section{Source of patients}

Patients admitted to an orthopedic surgery unit in a Spanish tertiary 450-bed hospital from August 1 to September 1, 2016, were included in the validation study. The number of chronic medications required for the study was calculated based on the sample size required to detect a kappa value that was significantly different from zero with $90 \%$ power. We aimed for a power of $90 \%$ in a two-tailed test for a kappa value of at least 0.6, where we estimated that the guidelines would have greater than $90 \%$ concordance with the views of the expert pharmacist. The calculated value was based on assessments of over 30 drugs [18]. Therefore, 140 drugs were analyzed in 20 patients (seven drugs per patient).

\section{Study procedure}

Each observer (i.e., pharmacist) received a dossier containing drug therapy and clinical information about each of the 20 patients to whom the guide was to be applied. The information about the patients comprised the following: the patient's ID number (1-20), age, sex, personal history, diagnosis-related drugs (DRGs), date of surgical intervention, and chronic treatment. The form included specific instructions that had to be marked with an $\mathrm{X}$ depending on whether the decision was made to continue $(\mathrm{C})$ or suspend $(\mathrm{S})$ treatment for the patient according to the guide for the continuity of care in perioperative medication management and the clinical information about the patient.

Patient treatments were reviewed blindly and independently by the eight pharmacists and compared with the gold standard (CM).

\section{Statistical analysis}

Statistical analyses were carried out using the software SPSS for Windows 20.0 (IBM SPSS). Cohen's kappa, with a confidence interval (CI) of $95 \%$, was used to analyze the concordance between each observer and the expert and between the eight observers. The degree of concordance was expressed as a numerical value of $k$, which ranged from 0.0 , indicating absolute discordance, to 1.0, indicating perfect concordance. A value of $>0.61$ indicated that the agreement was good [19]. For each item in the scale, the percent agreement was calculated as the number of times that the raters agreed on a rating (continue/discontinue) divided by the total number of ratings.

\section{Results}

\section{Development of the guidelines}

Some of the information reviewed came from clinical trials, but most was based on the opinions of experts, isolated clinical cases, or theoretical considerations according to experience with similar drugs [12]. There are consensus recommendations for several medications, whereas information is limited or controversial for 


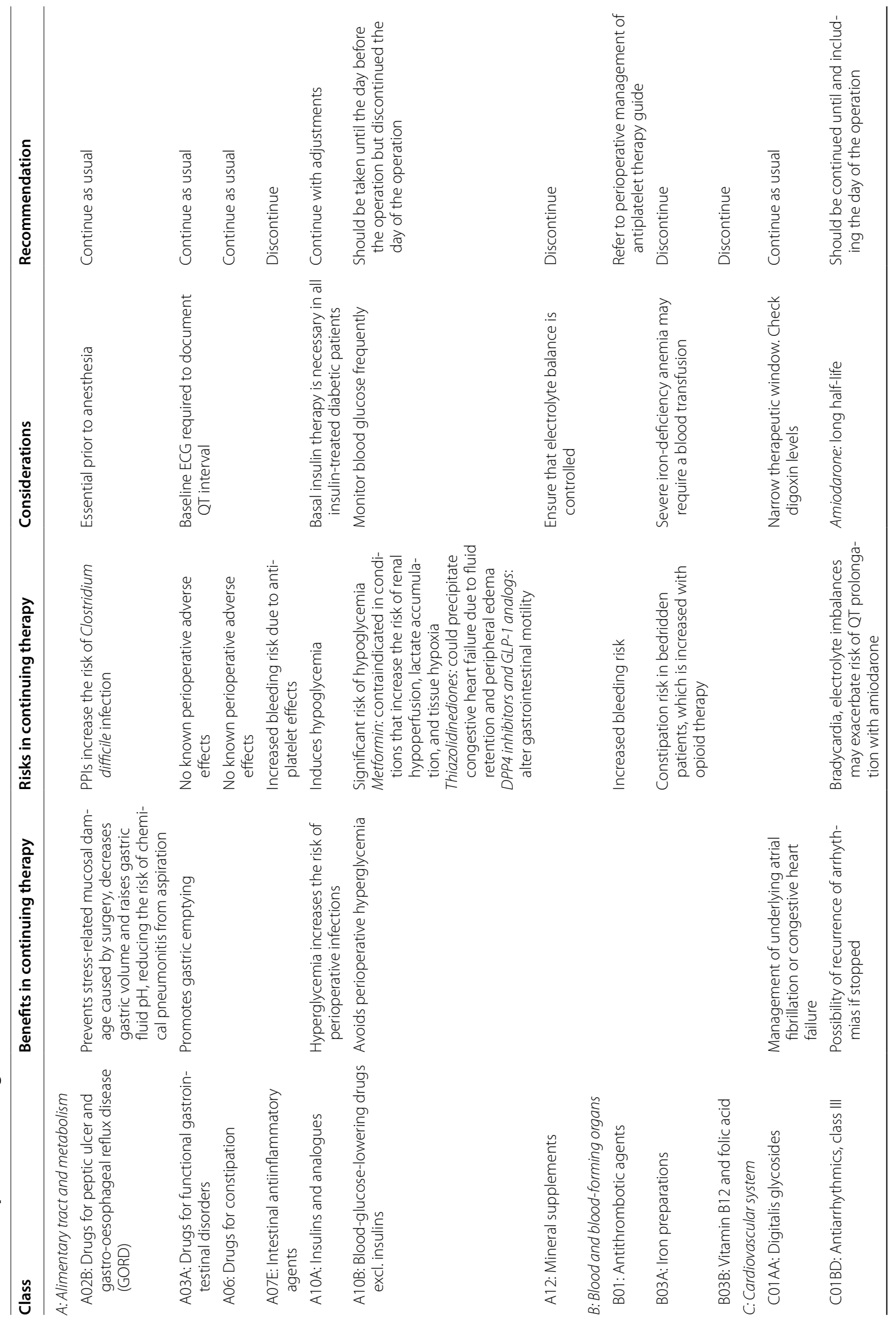




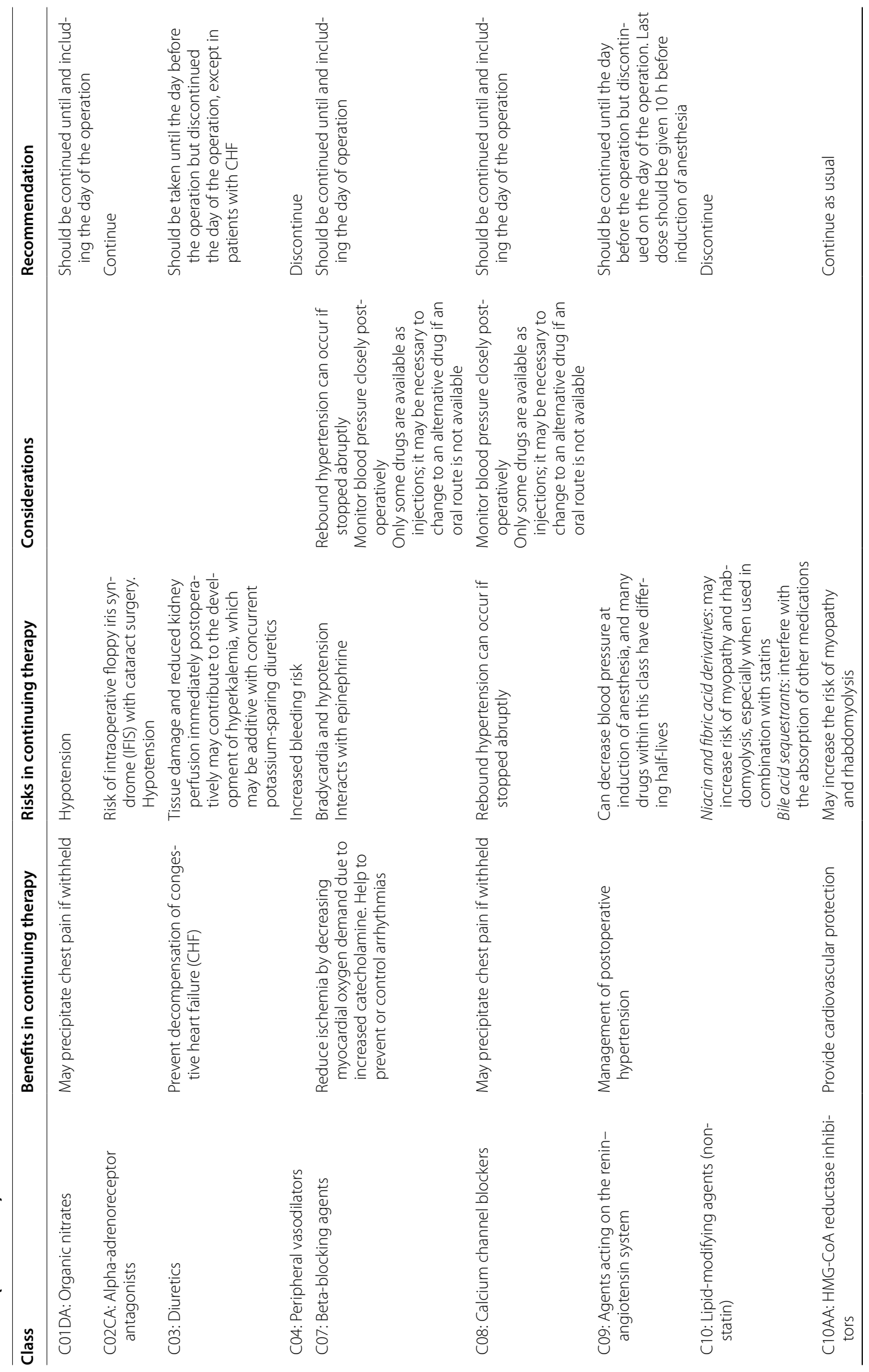




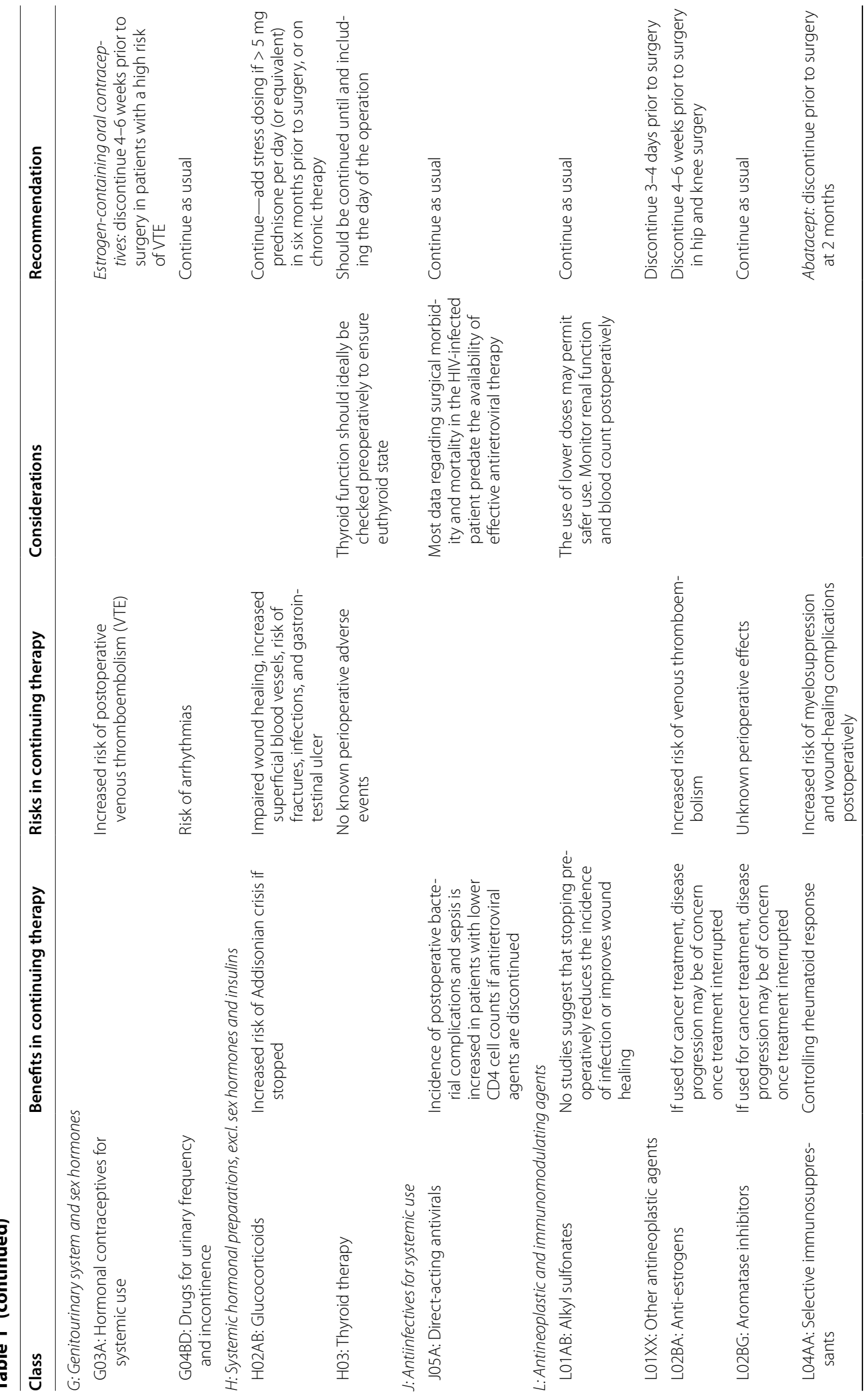




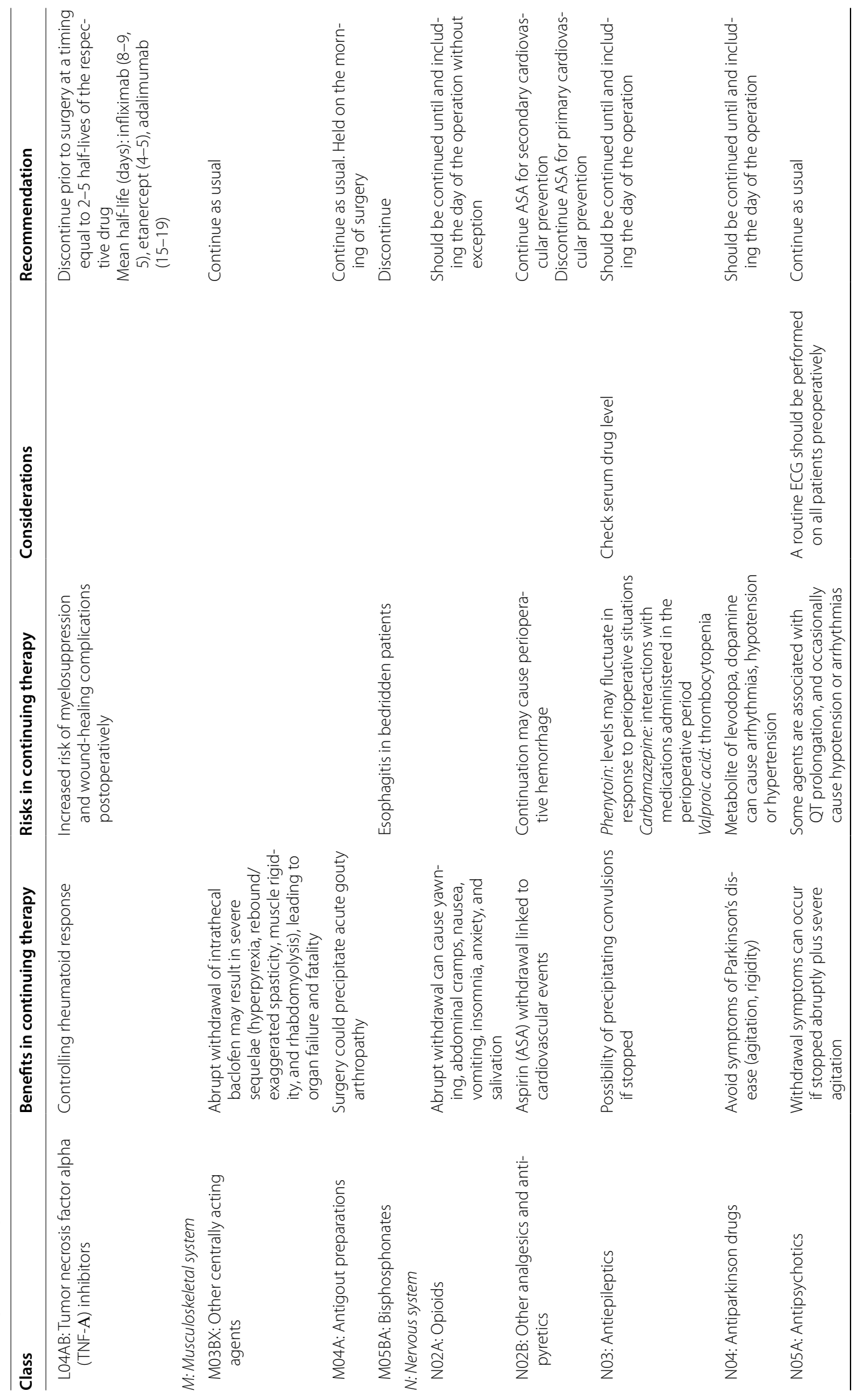




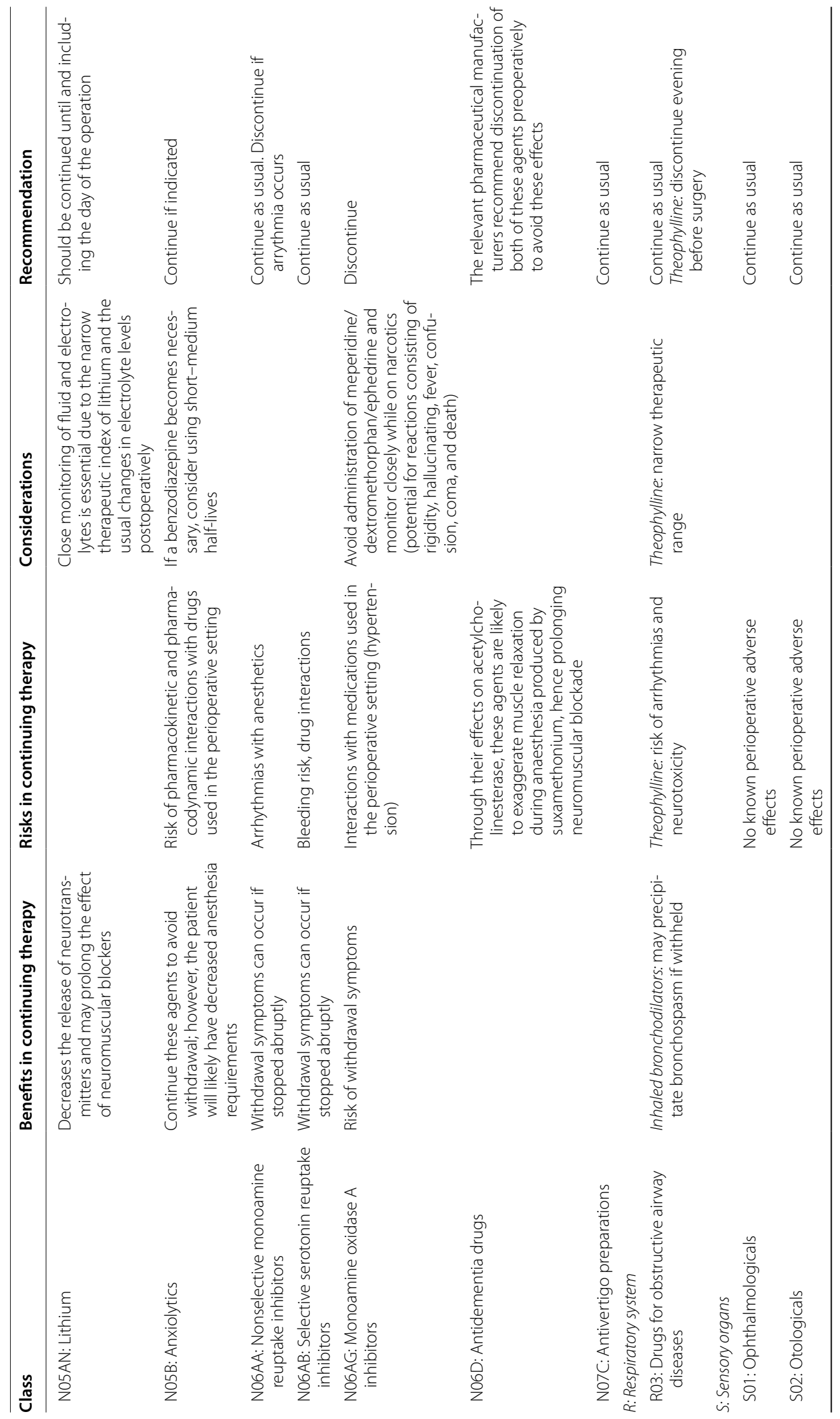




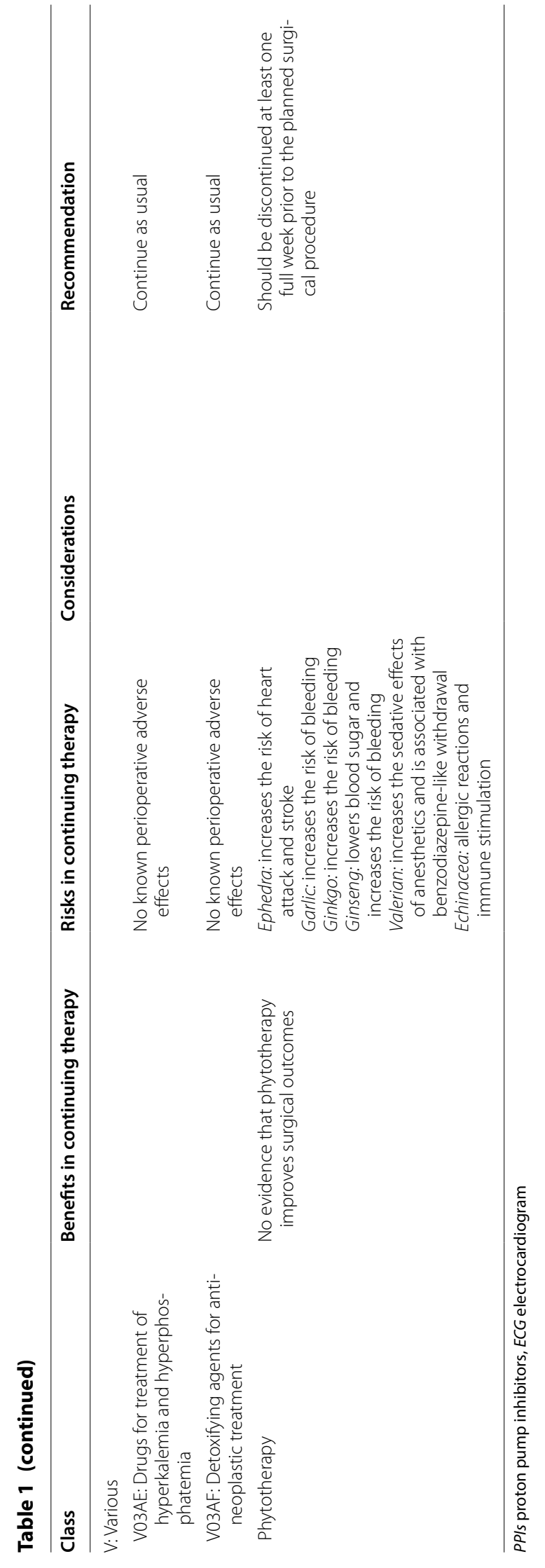


Table 2 Demographic and clinical characteristics of the 20 patients

\begin{tabular}{|c|c|c|c|c|c|}
\hline \multirow[t]{2}{*}{ DRG } & \multirow[t]{2}{*}{ n (\%) } & \multicolumn{2}{|c|}{ Sex } & \multirow{2}{*}{$\begin{array}{l}\text { Median } \\
\text { age } \\
\text { (years) }\end{array}$} & \multirow{2}{*}{$\begin{array}{l}\text { Median number } \\
\text { of comorbidities } \\
\text { per patient }\end{array}$} \\
\hline & & M & $\mathbf{F}$ & & \\
\hline 209_-Major joint and limb reattachment procedures for a lower extremity & $9(45.0)$ & 2 & 7 & 78.56 & 3.44 \\
\hline $\begin{array}{l}211 \text { - Hip and femur procedures excluding a major joint, age }>17 \text { years, without complica- } \\
\text { tions or comorbidities }\end{array}$ & $2(10.0)$ & 2 & 0 & 73 & 4.5 \\
\hline $\begin{array}{l}\text { 218- Lower extremity and humerus procedures excluding hip, foot, and femur, } \\
\text { age }>17 \text { years, with complications or comorbidities }\end{array}$ & $1(5.0)$ & 1 & 0 & 45 & 3 \\
\hline $\begin{array}{l}\text { 219-Lower extremity and humerus procedures excluding hip, foot, and femur, } \\
\text { age }>17 \text { years, without complications or comorbidities }\end{array}$ & $2(10.0)$ & 1 & 1 & 47.5 & 3 \\
\hline $\begin{array}{l}\text { 251_-Fracture, sprain, strain, and dislocation of forearm, hand, or foot, age }>17 \text { years, without } \\
\text { complications or comorbidities }\end{array}$ & $1(5.0)$ & 0 & 1 & 38 & 4 \\
\hline 807-Anterior and posterior spinal fusion combined, without complications & $1(5.0)$ & 0 & 1 & 86 & 4 \\
\hline 818-Hip replacement without complications & $4(20.0)$ & 0 & 4 & 81.25 & 3.75 \\
\hline Total & $20(100.0)$ & 6 & 14 & 70.45 & 3.60 \\
\hline
\end{tabular}

$D R G$ diagnosis-related group, $M$ male, $F$ female

others. Therefore, it is very important to assess the risk/ benefit ratio in each case, and it is possible that the final decision will not coincide with the general recommendations. For each drug, we selected several articles reviewing the full text of all relevants.

After reviewing the available information on the perioperative management of chronic medications in order to develop the guide, Table 1 was created. It divides the drugs into 12 main anatomical groups, 51 therapeutic groups, and a phytotherapy revision group.

\section{Validation of the guidelines \\ Sample of patients selected for the observational concordance study}

During the study period, 140 drugs were analyzed; those drugs were taken by 20 Caucasian patients (seven drugs/ patient) admitted to the orthopedic surgery unit.

The demographic (age and sex) and clinical (number of comorbidities) characteristics and diagnosis-related groups (DRGs) of the 20 patients are described in Table 2.

In total, there were 72 major comorbidities in the 20 patients, with an average of 3.6 comorbidities per patient. The most frequently detected comorbidity was hypertension, in 13 patients (65\%), followed by depression in six patients (30\%), and congestive heart failure and diabetes mellitus in five patients each (25\% each). There were also four cases of dyslipidemia (20\%) and four of atrial fibrillation (20\%). Only three cases of osteoporosis were detected (15\%), three of acute myocardial infarction (15\%), three of benign prostatic hyperplasia (3\%), and three of dementia/Alzheimer's disease (15\%). Vertiginous syndrome was observed in two patients (10\%), hiatal hernia in two patients (10\%), and anemia in two patients
(10\%). Finally, other comorbidities such as stroke, ulcer, acquired immune deficiency syndrome, Parkinson's disease, neoplasia, insomnia, hypothyroidism, gout, schizophrenia, epilepsy, Crohn's disease, and asthma/chronic obstructive pulmonary disease were detected in 12 patients (60\%) (data not shown).

\section{Drugs reviewed in the study}

The eight observers reviewed 140 drugs. The most prevalent therapeutic groups were group $\mathrm{N}$ (nervous system), 43 drugs (30.71\%); group C (cardiovascular system), 37 medicines (26.43\%); group A (alimentary tract and metabolism), 27 drugs (19.29\%); and group B (blood and blood-forming organs), 14 drugs (10\%) (Table 3 ).

\section{Agreement between observers}

Table 3 shows the percentage of absolute agreement between the eight pharmaceutical observers according to ATC group ( $n=140$ drugs). There was substantial or almost perfect interobserver agreement for the majority of the drug classes in the guide, such as the main anatomical groups $\mathrm{H}, \mathrm{L}, \mathrm{M}, \mathrm{R}$, and $\mathrm{S}$ as well as the main therapeutic groups A02, C05, C07, C08, G03, and N03. However, there was only fair or slight interobserver agreement for antidiarrheals, intestinal anti-inflammatory/anti-infective agents, antithrombotic agents, and other dermatological preparations.

\section{Agreement between each observer and the expert pharmacist}

Table 4 shows the agreement between each observer and the gold standard. We obtained an overall kappa value of 0.78 [95\% CI $(0.66,0.89)]$, which indicated almost perfect concordance between the observers and the expert 
Table 3 Absolute agreement among eight pharmaceutical observers following the application of the guide, listed according to ATC group

\begin{tabular}{|c|c|c|c|}
\hline Medicine class & $n(\%)$ & Kappa value & Agreement \\
\hline A02: Drugs for acid-related disorders & $16(11.4)$ & 1 & Almost perfect \\
\hline A07: Antidiarrheals, intestinal anti-inflammatory/anti-infective agents & $1(0.7)$ & $p<0.01$ & Poor \\
\hline A10: Drugs used in diabetes & $8(5.7)$ & 0.69 & Substantial \\
\hline A11: Vitamins & $1(0.7)$ & 1 & Almost perfect \\
\hline A12: Mineral supplements & $2(1.4)$ & 0.75 & Substantial \\
\hline B01: Antithrombotic agents & $10(7.1)$ & 0.16 & Slight \\
\hline B03: Antianemic preparations & $4(2.9)$ & 0.81 & Almost perfect \\
\hline C01: Cardiac therapy & $4(2.9)$ & 1 & Almost perfect \\
\hline C02: Antihypertensives & $1(0.7)$ & 1 & Almost perfect \\
\hline C03: Diuretics & $11(7.9)$ & 0.51 & Moderate \\
\hline C05: Vasoprotectives & $1(0.7)$ & 1 & Almost perfect \\
\hline C07: Beta-blocking agents & $1(0.7)$ & 1 & Almost perfect \\
\hline C08: Calcium channel blockers & $3(2.1)$ & 1 & Almost perfect \\
\hline C09: Agents acting on the renin-angiotensin system & $9(6.4)$ & 0.83 & Almost perfect \\
\hline C10: Lipid-modifying agents & $6(4.3)$ & 0.33 & Fair \\
\hline D11: Other dermatological preparations & $1(0.7)$ & $<0.01$ & Poor \\
\hline G03: Sex hormones and modulators of the genital system & $1(0.7)$ & 1 & Almost perfect \\
\hline G04: Urologicals & $2(1.4)$ & 0.55 & Moderate \\
\hline H02: Corticosteroids for systemic use & $2(1.4)$ & 1 & Almost perfect \\
\hline H03: Thyroid therapy & $3(2.1)$ & 1 & Almost perfect \\
\hline J05: Antivirals for systemic use & $1(0.7)$ & 0.50 & Moderate \\
\hline L01: Antineoplastic agents & $1(0.7)$ & 1 & Almost perfect \\
\hline L02: Endocrine therapy & $1(0.7)$ & 1 & Almost perfect \\
\hline L04: Immunosuppressants & $1(0.7)$ & 1 & Almost perfect \\
\hline M01: Anti-inflammatory and antirheumatic products & $1(0.7)$ & 1 & Almost perfect \\
\hline M04: Antigout preparations & $1(0.7)$ & 1 & Almost perfect \\
\hline N02: Analgesics & $10(7.1)$ & 0.60 & Moderate \\
\hline N03: Antiepileptics & $5(3.6)$ & 1 & Almost perfect \\
\hline N04: Antiparkinson drugs & $2(1.4)$ & 0.46 & Moderate \\
\hline N05: Psycholeptics & $14(10.0)$ & 0.93 & Almost perfect \\
\hline N06: Psychoanaleptics & $11(7.9)$ & 0.76 & Substantial \\
\hline N07: Other nervous system drugs & $1(0.7)$ & 0.50 & Moderate \\
\hline R03: Drugs for obstructive airway diseases & $1(0.7)$ & 1 & Almost perfect \\
\hline S01: Ophthalmologicals & $1(0.7)$ & 1 & Almost perfect \\
\hline Phytotherapeutics & $2(1.4)$ & 0.43 & Moderate \\
\hline
\end{tabular}

pharmacist, and the overall agreement was $89.30 \%$ for the 140 drugs.

\section{Discussion}

In this study, we developed a valid guide for the continuity of care in perioperative medication management, based on the available evidence and approved by a committee including specialists and physicians from the Department of Anesthesiology. This guide was validated by demonstrating that its use resulted in high concordance among eight pharmacists in decisions made regarding 140 drugs taken by 20 chronic inpatients. For the set of pharmaceutical interventions considered by the eight observers, we obtained an overall agreement of $86.9 \%$ and a kappa value of 0.7 . When we compared the decisions made by the individual observers to those made by the expert pharmacist, the kappa value (a measure of the agreement between two observers) increased to 0.8 [95\% CI $(0.7,0.9)]$, indicating almost perfect concordance, and the overall agreement was $89.3 \%$. 


$\begin{aligned} & \text { Table } 4 \text { Concordance } \\
& \text { and the expert pharmacist } \\
& \text { between }\end{aligned}$ the eight
\begin{tabular}{lllllll} 
Observer & Kappa value & SE & $\boldsymbol{p}$ & $\mathbf{9 5 \%} \mathbf{C l}$ & Agreement \\
\hline Observer 1 & 0.82 & 0054 & $<0.001$ & $0.71-0.92$ & Almost perfect \\
Observer 2 & 0.83 & 0050 & $<0.001$ & $0.73-0.93$ & Almost perfect \\
Observer 3 & 0.75 & 0059 & $<0.001$ & $0.64-0.87$ & Substantial \\
Observer 4 & 0.77 & 0060 & $<0.001$ & $0.65-0.88$ & Substantial \\
Observer 5 & 0.79 & 0057 & $<0.001$ & $0.68-0.90$ & Substantial \\
Observer 6 & 0.81 & 0054 & $<0.001$ & $0.70-0.91$ & Almost perfect \\
Observer 7 & 0.74 & 0062 & $<0.001$ & $0.62-0.86$ & Substantial \\
Observer 8 & 0.75 & 0.751 & $<0.001$ & $0.63-0.87$ & Substantial \\
\hline
\end{tabular}

SE standard error, $95 \% \mathrm{Cl}$ confidence interval

A similar study was conducted in a tertiary hospital in Australia by Lindsay et al. [18] during 2013, where the aims were to design and validate deprescribing guidelines for cancer patients in palliative care and to identify potentially inappropriate medicines. That prospective, noninterventional cohort study comprised four major stages (similar to our study): developing the OncPal Deprescribing Guidelines based on current evidence; the prospective recruitment of consecutive palliative cancer inpatients; the assessment of all medications by a panel of medical experts to identify potentially inappropriate medicines; and an evaluation of the guidelines by concordance testing. The OncPal Deprescribing Guidelines matched $94.0 \%$ of the expert panel's recommendations for 617 medicines, and the kappa value was 0.8 [95\% CI $(0.8,0.9)]$, a similar result to ours. However, the difference from our study was that the Australian observers did not receive a training session regarding the guidelines because they were considered experts. In our study, we included pharmacists with a range of expertise in the evaluations, so the training course was crucial to achieving these great results. However, although concordance was very high for the majority of the medicine classes, it was low for antidiarrheals, intestinal anti-inflammatory/ anti-infective agents, antithrombotic agents, and other dermatological preparations. When interpreting our results, it is important to note that the observers had no previous experience with this analysis, and that they carried out the observations that form the basis of this study only after a period of formal training. We feel that with additional experience, the results would have been better in all the drug classes.

It is important to note that his study has various limitations:

- This study focused only on the diagnosis of each patient undergoing an orthopedic procedure. Thus, previous comorbidities could have affected patient health.

- This study should have considered patients from different ethnic groups, given that the pharmacokinetics and pharmacodynamics of drugs can vary among ethnic groups [20].

- This study was carried out in just one hospital; in the future, the guide should be validated further and its reproducibility should be checked by applying it in different clinical settings in the same hospital and in different hospitals.

In summary, we have developed a guide for the continuity of care in perioperative medication management as a tool to improve the rationalization of medicines in the perioperative environment. Given the high number of medical comorbidities suffered by the elderly, and the associated polypharmacy and perioperative risks, it is important to ensure optimal management of the pre-existing medical conditions of these patients before and during surgery. Applying the guide developed here minimizes chronic disease progression or decompensation, interactions with anesthesia, and perioperative complications. The validation of this guide showed a high level of concordance between the trained observers and the expert who had previously classified the medication. Formal training seems to be essential to assure consistency of medication management, even among pharmacists with different levels of expertise.

\section{Authors' contributions}

CMC carried out the guide development and revision process, participated in the concordance study and the analysis of the results and drafted the manuscript. ANR carried out the guide development and revision process. BL carried out the analysis of the results and drafted the manuscript. All authors read and approved the final manuscript.

\section{Author details}

${ }^{1}$ Department of Pharmacy Services, University Hospital of Elche, Camino de la Almazara 11, 03203 Elche, Spain. ${ }^{2}$ Department of Public Health, History of Science and Gynecology, Miguel Hernández University, Alicante, Spain. ${ }^{3}$ CIBER en Epidemiología y Salud Pública (CIBERESP), Madrid, Spain.

\section{Competing interests}

The authors declare that they have no competing interests.

\section{Ethics approval and consent to participate}

All procedures performed in studies involving human participants were in accordance with the ethical standards of the institutional and/or national research committee and with the 1964 Helsinki Declaration and its later amendments or comparable ethical standards.

This study is part of the research project "Clinical impact of pharmaceutical intervention in the adequacy of treatment in elderly patients hospitalized."This research project received a favorable report from the Clinical Research Ethics Committee of the Hospital General Universitario de Elche on 29 January 2015.

\section{Funding}

The project did not receive any financial funding. 


\section{Informed consent}

Formal informed consent was not required for this study. Patients' chronic medications were retrospectively reviewed and data were recorded. Patients had already been operated on and all patients had already been discharged from hospital. A retrospective review of the clinical histories was carried out.

\section{Publisher's note}

Springer Nature remains neutral with regard to jurisdictional claims in published maps and institutional affiliations.

Received: 11 August 2017 Accepted: 5 March 2018

Published online: 17 July 2018

\section{References}

1. World Health Organization. Global Health Observatory $(\mathrm{GHO})$ data. Life expectancy. http://www.who.int/gho/es/. Accessed 15 Feb 2017

2. Caughey GE, Vitry Al, Gilbert AL, Roughead EE (2008) Prevalence of comorbidity of chronic diseases in Australia. BMC Public Health. 8(221):1-13

3. Ministerio de Sanidad, Servicios Sociales e lgualdad: Subdirección General de Información Sanitaria e Innovación. Informe sobre la hospitalización-Registro de Altas-CMBD Año 2013. Serie Informes Breves CMBD. 2015. http://www.msssi.gob.es/estadEstudios/estadisticas/cmbdhome. htm. Accessed 20 July 2016

4. Department of Health (UK). Supporting people with long term conditions. An NHS and social care model to support local innovation and integration. 2005. http://www.dh.gov.uk/prod_consum_dh/groups/dh_digit alassets/@dh/@en/documents/digitalasset/dh_4122574.pdf. Accessed 10 Aug 2016

5. Avellana Zaragoza JA, Ferrández Portal L (2007) Guía de buena práctica clínica en geriatría. Anciano afecto de fractura de cadera, 1st edn. Sociedad Española de Geriatría y Gerontología/Sociedad Española de Cirugía Ortopédica y Traumatología/Elsevier Doyma, Madrid/Madrid/Barcelona

6. USP Patient Safety CAPSLink. US Pharmacopeia. 2005. http://www.usp. org/patientSafety/newsletters/capsLink. Accessed 20 Feb 2016

7. World Health Organization. High 5s Project: action on patient safety. 2006. http://www.who.int/patientsafety/implementation/solutions/ high5s/ps_high5s_project_overview_fs_2010_en.pdf. Accessed 25 May 2016
8. Australian Commission on Safety and Quality in Health Care. World Health Organization's High 5s Medication Reconciliation Project. 2015. http://www.safetyandquality.gov.au/our-work/medication-safety/medic ation-reconciliation/who-high-5s-medication-reconciliation-program/. Accessed 10 Feb 2015

9. Kennedy JM, Van Rij AM, Spears GF, Pettigrew RA, Tucker IG (2000) Polypharmacy in a general surgical unit and consequences of drug withdrawal. Br J Clin Pharmacol 49(4):353-362

10. Kroenke K, Gooby-Toedt D, Jackson JL (1998) Chronic medications in the perioperative period. South Med J 91(4):358

11. Castanheira L, Fresco P, MacEdo AF (2011) Guidelines for the management of chronic medication in the perioperative period: systematic review and formal consensus. J Clin Pharm Ther 36(4):446-467

12. MulukV, MacPherson DS. Perioperative medication management. 2012 https://www.uptodate.com. Accessed 31 Oct 2014

13. Spell NO 3rd (2001) Stopping and restarting medications in the perioperative period. Med Clin North Am 85(5):1117

14. Smith MS, Muir H, Hall R (1996) Perioperative management of drug therapy, clinical considerations. Drugs. 51(2):238

15. EphMRA. Anatomical classification. 2016. http://www.ephmra.org/Anato mical-Classification. Accessed 15 Mar 2016

16. Ministerio de Sanidad, Servicios Sociales e Igualdad. Informe annual del Sistema Nacional de Salud. 2015. http://www.msssi.gob.es/estadEstud ios/estadisticas/sisInfSanSNS/tablasEstadisticas/InfAnSNS.htm. Accessed 15 Jan 2016

17. Lievano Rojas JL. Manejo perioperatorio de medicamentos crónicos en cirugía ortopédica mayor. Revision sistemática de la rrhythmia. Investigación programa postgrado Ortopedia y Traumatología. Universidad del Rosario. 2015. http://www.repository.urosario.edu.co/bitstream/handl e/10336/10160/1032384445-2015.pdf. Accessed 15 Jan 2015

18. Lindsay J, Dooley M, Martin J et al (2015) The development and evaluation of an oncological palliative care deprescribing guideline: the "OncPal deprescribing guideline". Support Care Cancer 23:71-78

19. Cohen J (1960) A coefficient of agreement for nominal scales. Educ Psychol Meas 20(1):37-46

20. Yasuda SU, Zhang L, Huang SM (2008) The role of ethnicity in variability in response to drugs: focus on clinical pharmacology studies. Clin Pharmacol Ther 84(3):417-423

\section{Submit your manuscript to a SpringerOpen ${ }^{\odot}$ journal and benefit from:}

- Convenient online submission

- Rigorous peer review

- Open access: articles freely available online

- High visibility within the field

- Retaining the copyright to your article

Submit your next manuscript at $\boldsymbol{\nabla}$ springeropen.com 